В.В. Тихонова, Ю.П. Финашутина, Л.А. Кесаева

ФГБУ «Национальный медицинский исследовательский центр онкологии им. Н.Н. Блохина» Минздрава России; Россия, 115478 Москва, Каширское шоссе, 24

К о н та к ты : Лаура Артуровна Кесаева kelar-22@mail.ru

Важной проблемой при терапии любого типа опухоли является возникновение первичной или вторичной резистентности, которая зачастую связана с изменением функционирования целевых генов. В связи с этим встает вопрос о понимании функциональных внутриклеточных взаимодействий генов и белков в онкологических процессах и возникновении резистентности к лечению. Для поиска целевых белков таргетной терапии необходимо идентифицировать таких участников сигнальной жизни клетки, функциональное состояние которых различно в норме и при канцерогенезе. Также важно, чтобы определение этих участников не было артефактом вследствие терапии опухолей или культивирования клеточных линий и существовала возможность оказывать на них прямое воздействие, дающее комплексный эффект. Кроме того, необходимо изучить изменения, происходящие с этими участниками, к которым относятся киназы семейства SRC LYN и ген эстрогенового рецептора a, во время терапии в целях преодоления возникающей резистентности.

Цель обзора - изучение роли генов киназы семейства SRC LYN и эстрогенового рецептора а в онкологических процессах и возникновении резистентности к терапии.

Ключевые слова: ген эстрогенового рецептора а, ген киназы семейства SRC LYN, мутации, резистентность, прогноз терапии

Для цитирования: Тихонова В.В., Финашутина Ю.П., Кесаева Л.А. Рецептор эстрогенов ERa и киназа LYN: участие в механизмах канцерогенеза и использование в качестве мишеней в таргетной терапии при онкологических заболеваниях. Успехи молекулярной онкологии 2021;8(3):44-59. DOI: 10.17650/2313-805X-2021-8-3-44-59.

\title{
LYN kinase and estrogen receptor ERa: involvement in carcinogenesis and potential therapeutic target for tumors
}

\section{V.V. Tikhonova, Y.P. Finashutina, L.A. Kesaeva \\ N.N. Blokhin Russian Cancer Research Center, Ministry of Health of Russia; 24 Kashirskoe Shosse, Moscow 115478, Russia}

Conta cts: $\quad$ Laura Arturovna Kesaeva kelar-22@mail.ru

Primary or secondary resistance is an important problem when treating any type of tumor. It is often associated with changes in target genes' functioning. This raises the question of understanding functional intracellular interactions of genes and proteins in oncological processes and therapeutic resistance occurring. When searching target proteins of targeted therapy, it is necessary to identify biomolecules, participating in cell signaling life, which differ significantly in normal and oncological processes and interact with a large number of pathways. It is also important that these biomolecules are not an artifact of tumor therapy or cell line cultivation, and that it is possible to influence them directly, obtaining complex effect. In addition, it is important to study changes occurring during therapy with the biomolecules, which include proto-oncogene of SRC family kinase LYN and gene of the estrogen receptor a ESR1. All these factors may help to overcome the emerging resistance.

Objective - to study the way genes of SRC kinase LYN and estrogen receptor a ESR1 influence oncological processes and occurrence of therapeutic resistance. 
Key words: estrogen receptor a, SRC kinase, LYN, mutations, resistance, therapy prognosis

For citation: Tikhonova V.V., Finashutina Y.P., Kesaeva L.A. LYN kinase and estrogen receptor a: involvement in carcinogenesis and potential therapeutic target for tumors. Uspekhi molekulyarnoy onkologii = Advances in Molecular Oncology 2021;8(3):44-59. (In Russ.). DOI: 10.17650/2313-805X-2021-8-3-44-59.

\section{ВВЕДЕНИЕ}

Химиотерапия и таргетная терапия (ТТ) лейкозов и солидных опухолей заметно эволюционировали в течение последних десятилетий. Однако неизменным остается возникновение первичной или вторичной резистентности к лечению, которая является важной проблемой при любом типе опухоли. Поскольку терапия, особенно таргетная, воздействует на конкретные белки, участвующие в сигнальных путях клетки, или на определенные фазы клеточного цикла, резистентность зачастую связана с изменением функционирования целевых участников: с трансформацией их структуры, интенсивности экспрессии, а также заменой их роли альтернативными сигнальными путями. В связи с этим важно понимать функциональные внутриклеточные взаимодействия в норме и при онкологическом процессе, а также механизмы возникновения резистентности к терапии.

Внутриклеточная жизнь может быть описана как сложная сеть взаимодействий между генами и белками. Опухолевая клетка, как правило, имеет несколько точек нарушенных взаимодействий, что приводит к высокой пролиферации, нечувствительности к действиям иммунитета, эпителиально-мезенхимальному переходу (ЭМП) и др. Таргетная терапия направлена на нейтрализацию этих специфических нарушений, необходимых для того, чтобы раковая клетка оставалась жизнеспособной. Идеальные целевые белки для данной терапии должны быть такими, чтобы их подавление значительно влияло на выживаемость и работоспособность опухолевых клеток и в то же время оказывало меньшее воздействие на нормальные клетки.

Для определения таких мишеней, как правило, сравнивают уровни экспрессии генов в нормальных и опухолевых клетках. Помимо этого рекомендуется обращать внимание на высокую степень связности в сети генов, поскольку подавление их экспрессии затрагивает сразу несколько процессов, важных для функционирования раковой клетки. Такие гены взаимодействуют с большим количеством других генов в подмножествах образцов и выступают концентраторами в связанной генной сети. Чем больше количество связей гена, тем сильнее эффект от его блокирования [1].

Для исследования онкологических процессов важны рассмотрение профилей экспрессии и секвенирование нового поколения. С одной стороны, сравнение генетических профилей нормальных и опухолевых тканей позволило определить большое количество новых генов, которые могут участвовать в этих процессах. С другой стороны, быстрое накопление информа- ции привело к недостаточному пониманию роли открытых генов в возникновении, течении и терапии злокачественных новообразований. Масштабное исследование лекарственных реакций, проведенных на геномно охарактеризованных опухолевых клеточных линиях, тем более не может быть полностью информативным, поскольку клеточные линии несут мутационный «багаж» в виде сотен и тысяч геномных изменений, связанных с их культивированием, что затрудняет поиск связи лекарственного ответа с наличием одной инициирующей мутации [2].

Еще одной проблемой является поиск средств индивидуальной терапии рака при отсутствии прямых мишеней, таких как факторы транскрипции или другие некиназные белки. В этом случае альтернативным методом является ингибирование других участков сигнальных путей с использованием функциональной геномики для рассмотрения взаимодействия мутантных генов и их сигнального окружения [2].

В связи с этим очень важной задачей является идентификация таких участников сигнальных сетей клетки, функциональное состояние которых различно в норме и при канцерогенезе и которые взаимодействуют с большим количеством путей. Также необходимо, чтобы определение этих участников не было артефактом вследствие терапии опухолей или культивирования клеточных линий и существовала возможность оказывать на них прямое воздействие, дающее комплексный эффект. Кроме того, нужно изучить изменения, происходящие с этими участниками во время терапии для преодоления резистентности.

K таким участникам сигнальных сетей относятся протоонкогены киназ семейства SRC (LYN, YES1, HCK, FYN, LCK), имеющие высокую степень связанности в генных цепях, дефекты которых встречаются при многих онкологических заболеваниях, в том числе при базальноподобном и HER2-позитивном раке молочной железы (РМЖ). Поскольку это киназы, на них можно оказывать прямое воздействие, например, осуществлять ингибирование LYN с помощью дазатиниба. Другим примером участников сигнальных путей при люминальном подтипе А РМЖ выступают гены ESR1, HER2, EGFR, FOS. Для терапии HER2-положительных опухолей используют герцептин; ESR1-позитивных люминальных подтипов РМЖ - тамоксифен. Известно, что лечение тамоксифеном люминального подтипа В РМЖ менее успешно, чем люминального подтипа А. Показатель связанности ESR1 с другими генами составляет 6,94 при люминальном подтипе А РМЖ и только 3,44 при люминальном подтипе В, хотя ESR1 одинаково сверхэкспрессирован в обоих 
случаях. Согласно этим данным, причина, по которой тамоксифен не работает так же хорошо при люминальном подтипе В, как и при люминальном подтипе А, может заключаться в том, что в первом случае опухоль в меньшей степени зависит от $E S R 1$, чем во втором. Иными словами, количество других генов, зависящих от ESR1, при люминальном подтипе В РМЖ намного меньше, чем при люминальном подтипе А. Следовательно, в первом случае РМЖ менее восприимчив к лекарствам, таким как тамоксифен, которые функционируют, блокируя путь эстрогена [1].

В этом обзоре мы продолжаем анализировать корреляции точечных мутаций в генах $L Y N$ и $E S R 1$ с резистентностью к эндокринной терапии рака яичников и перспективы использования mutESR1 и mutLYN в качестве предиктивных маркеров терапии. Этой актуальной проблеме посвящена также работа Е.А. Шестаковой [3]. Для более широкого обсуждения данной темы нужно рассмотреть молекулярные причины вовлечения генов $L Y N$ и $E S R 1$ в процессы канцерогенеза и резистентности, а также их взаимодействие с другими участниками метаболических путей. Это необходимо для определения прогноза лечения, преодоления лекарственной резистентности и поиска более эффективных ингибиторов эстрогенового рецептора $\alpha(E R \alpha)$ и киназы LYN, которые можно использовать в комбинации с другими противоопухолевыми лекарствами.

В связи с вышесказанным цель данного обзора изучение роли генов киназы семейства SRC LYN и $\mathrm{ER} \alpha$ в онкологических процессах и возникновении резистентности к терапии.

\section{ФУНКЦИОНИРОВАНИЕ LYN И ERA}

В НОРМАЛЬНЫХ И ТРАНСФОРМИРОВАННЫХ КЛЕТКАХ

Ген $L Y N$ расположен в хромосоме 8q13. Он кодирует белок из киназ семейства SRC и является важным посредником передачи сигналов для регулирования различных клеточных процессов, таких как пролиферация, дифференциация, апоптоз, миграция и метаболизм. Нерецепторная тирозин-протеинкиназа LYN передает сигналы от рецепторов клеточной поверхности и играет большую роль в регуляции врожденных и адаптивных иммунных реакций, гемопоэза, передачи сигналов интегрина, а также ответов на факторы роста, повреждение ДНК и действие генотоксических агентов. Например, $L Y N$ инициирует каскад событий при связывании лиганда с В-клеточным рецептором (рис 1). Киназа LYN функционирует в основном в качестве отрицательного регулятора, но также может действовать как активатор в зависимости от контекста [4]. Эта двойственность иллюстрируется дефектом B-клеток у LYN ${ }^{-/-}$-мышей. В данном случае LYN необходима для ингибирования В-клеточного рецептора. И наоборот, для В-клеток, экспрессирующих сверхактивную киназу LYN $\left(\mathrm{LYN}^{+/+}\right)$, характерна повышенная активность стимуляторов В-клеточных рецепторов.
LYN играет большую роль в регуляции дифференцировки, пролиферации, выживания и апоптоза В-клеток. У трансгенных мышей дефицит экспрессии LYN приводит к накоплению незрелых В-клеток в костном мозге и селезенке на транзиторной стадии Т1. Трансгенное снижение экспрессии Bcl-2 вызывает резкое увеличение количества В-клеток и возобновляет транзиторную стадию Т2. Исследования показывают, что LYN способствует отбору и выживанию зрелых В-клеток, но негативно влияет на их толерантность и активацию [5]. Эта киназа активно функционирует в большинстве кроветворных клеток (а именно в клетках-предшественниках) посредством воздействия на передачу сигналов на киназу с-KIT, а также в зрелых клетках в передаче сигналов от рецепторов к интегрину, например, в эритроцитах, тромбоцитах, тучных клетках и макрофагах. Следовательно, LYN играет большую роль в регуляции гемопоэтических нарушений. Эта киназа является важным регулятором аутоиммунных заболеваний, таких как астма и псориаз, из-за ее способности влиять на передачу сигналов иммунных клеTOK [6].

Влияние эстрогенов на клетку реализуется через их взаимодействие с рецепторами (в том числе с $E R \alpha$ ), которые, в свою очередь, активируют гены-мишени во многих тканях. Ген $E S R 1$ локализуется на 6-й хромосоме и кодирует ER $\alpha$. Рецептор представляет собой трансмембранный белок, C-конец которого содержит центр связывания с лигандом, а $\mathrm{N}$-конец содержит несколько доменов, способствующих увеличению транскрипционной активности ряда генов. Присоединение гормона к рецептору вызывает диссоциацию комплекса рецептора с белком HSP90. Далее рецептор в виде гетеродимера взаимодействует с эстроген-респонсивным элементом, увеличивая экспрессию необходимых генов. Показано, что повышенная экспрессия ER $\alpha$ сопровождает процессы трансформации во многих тканях и что его количество может измениться в ответ на повышение концентрации эстрогенов, что, в свою очередь, приводит к усилению пролиферации в тканяхмишенях. Одним из механизмов этого процесса служит увеличение активности ароматазы [7].

Поскольку LYN и ER $\alpha$ являются важными участниками сигнальной сети клетки для регулирования различных клеточных процессов, они часто участвуют в канцерогенезе.

Белки семейства киназ SRC регулируют 4 основные клеточные функции, которые в конечном счете контролируют поведение опухолевых клеток: пролиферацию, адгезию, инвазию и подвижность [8]. Гиперэкспрессия LYN ассоциирована с ЭМП и коррелирует с более низкими показателями выживаемости при PMЖ. В связи с этим ряд тирозинкиназ SRC, в том чсиле YES1 и LYN, являются хорошими терапевтическими мишенями в подгруппах базальноподобного и/или HER2-позитивного РМЖ. Показано, что киназа LYN необходима для миграции и инвазии клеток 


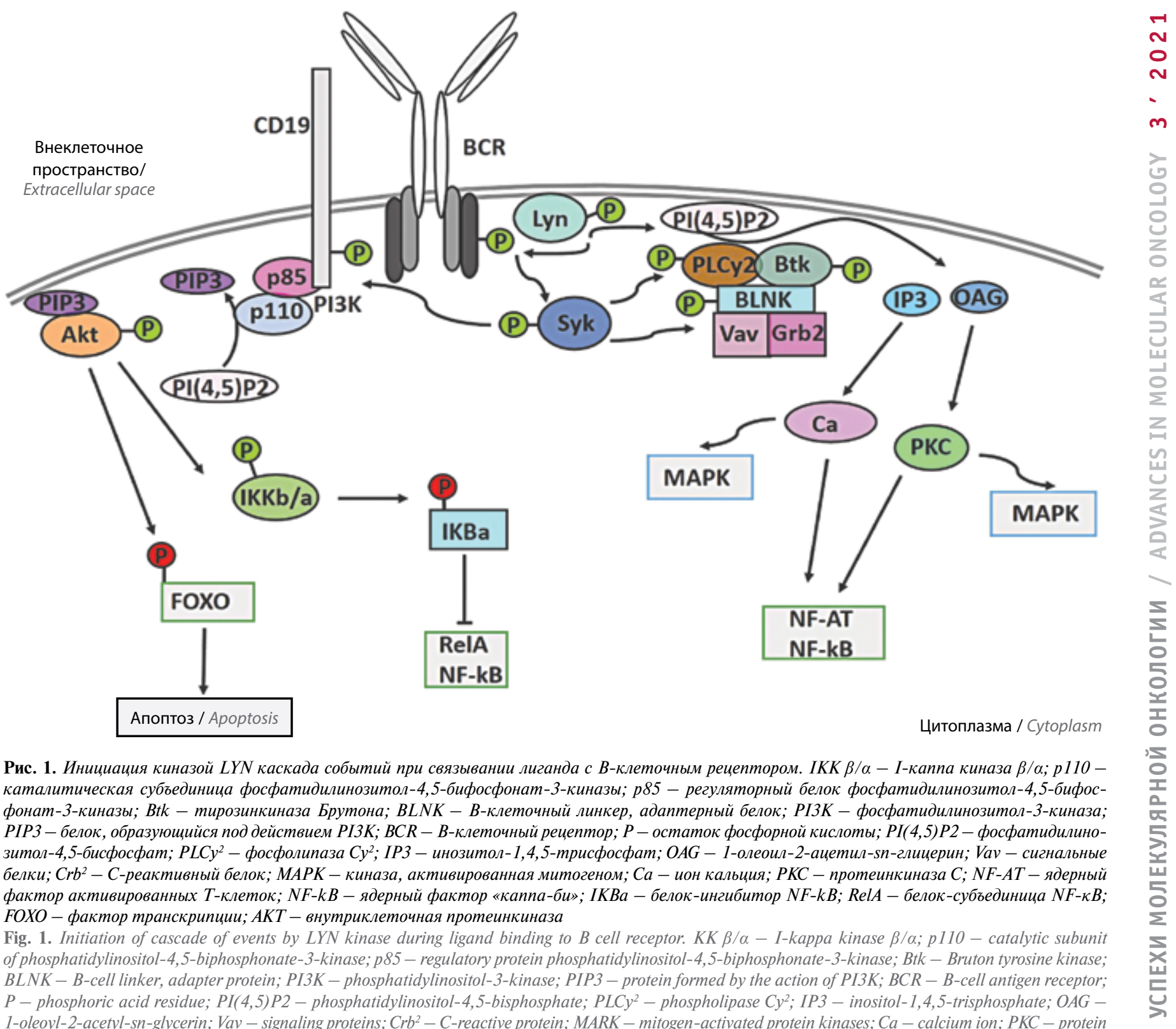
kinase $C$; NF-AT - nuclear factor of activated T cells; NF-KB - nuclear factor $\kappa B ;$ IkBa - protein-inhibitor of NF-KB; RelA - protein-subunit of NF-KB; FOXO - forkhead box protein O1; AKT-intracellular protein kinase

в базально-подобных клеточных линиях РМЖ, но не для пролиферации [9]. Активация и повышенная экспрессия SRC-киназ были также описаны в клеточных линиях рака яичников (РЯ) человека и клинических образцах этой опухоли. Кроме того, у пациентов с РЯ и гиперэкспрессией SRC также наблюдался худший прогноз течения заболевания [10].

Иммуногистохимические исследования показывают, что экспрессия LYN значительно повышена в тканях рака шейки матки по сравнению с клетками, прилегающими к нормальным тканям шейки матки, и с нормальными тканями шейки матки, а также что повышенная экспрессия LYN коррелирует с дифференциацией и стадией рака шейки матки. Ингибирование киназы LYN снижает пролиферацию, миграцию и инвазию клеток, и наоборот, избыточная экспрессия
LYN способствует этим процессам. Согласно результатам исследования in vivo [4], избыточная экспрессия LYN активирует рост опухоли, в то время как нокдаун LYN его ингибирует.

Высокая ядерная экспрессия LYN в клетках светлоклеточного рака почки и нижестоящего маркера активации паксиллина были связаны со снижением показателей выживаемости, и наоборот, повышенная цитоплазматическая экспрессия других членов семейства SRC-киназ и нижестоящего маркера активации фокальной адгезионной киназы (FAK) - с улучшением этих показателей [11].

Избыточная экспрессия LYN была также обнаружена при других видах рака, таких как хронический миелолейкоз [12], колоректальный рак [13], рак простаты [14] и желудка [15]. 
Эпителиально-мезенхимальный переход - переход поляризованных эпителиальных клеток в миграционный, фибробластоидный фенотип - считается ключевым процессом, стимулирующим инвазивность и метастазирование опухолевых клеток. В мезенхимальных линиях РMЖ RNAi-опосредованный нокдаун LYN ингибировал миграцию и инвазию клеток, но не пролиферацию. Дазатиниб, ингибирующий эту киназу, также блокировал инвазию, но не пролиферацию клеток. Нокдаун LYN приводил к снижению экспрессии мезенхимальных маркеров виментина (на 65-75 \%) и N-кадгерина (на 50-70 \%). Это позволяет предположить, что LYN опосредует только часть мезенхимального фенотипа [9]. Также было установлено, что активность данной киназы важна для установления фенотипа клеток при различных видах гемобластозов, включая острый миелоидный лейкоз, хронический миелоидный лейкоз и В-клеточный лимфоидный лейкоз (B-ХЛЛ). LYN также может стать потенциальной мишенью для терапии при раке простаты, толстой кишки и глиобластоме [6].

Эстрогеновый рецептор $\alpha$ также участвует в процессах онкогенеза. Приблизительно $75 \%$ случаев РМЖ являются ER $\alpha$-положительными, а присутствие химерного гена $E S R 1-C C D C 170$ отмечено у пациентов с диагнозом «серозный рак яичников высокой степени тяжести» [16]. Рак яичников является основной причиной смерти пациентов при гинекологических злокачественных новообразованиях. Гипоксия тесно связана со злокачественным ростом клеток. Тем не менее молекулярный механизм регуляции гипоксии клеток яичников остается неясным. В ходе биоинформатического исследования сигнальных путей, участвующих в регуляции гипоксии [17], было выявлено несколько ключевых белков-участников этого процесса, в том числе ESR1, MMP2, ErbB2, MYC, VIM, CYBB, EDN1, SERPINE1 и PDK. Таким образом, гипоксия может способствовать пролиферации опухолевых клеток яичников, влияя на функции инвазии и адгезии через нарушения регуляции сигнальных путей. На модели ксенографтов РЯ было показано, что на ранней стадии лечения препаратами платины активность сигнальных путей ESR1 и ERBB снижается [18]. При этом изменения в WNT-сигнальном пути и изменения маркеров инвазии наблюдаются позже. Данные результаты свидетельствуют о потенциальной терапевтической роли ингибиторов таких путей, которые могут продлевать эффекты химотерапии с использованием препаратов платины.

\section{ВЗАИМОДЕЙСТВИЕ LYN И ЕR М МЕЖДУ СОБОЙ И С ДРУГИМИ УЧАСТНИКАМИ СИГНАЛЬНЫХ ПУТЕЙ}

Члены семейства нерецепторных SRC-киназ распространяют многочисленные внутриклеточные сигналы от рецепторов факторов роста и стероидных гормонов, рецепторов, связанных с G-белком, комплексов интегрина, а также через взаимодействия с компонентами цитоскелета [19]. Эти киназы модулируют передачу сигнала через множество известных онкогенных путей, включая EGFR, HER2, PDGFR, FGFR и VEGFR. Был идентифицирован широкий спектр субстратов SRC, которые регулируют клеточный рост, адгезию, инвазию и подвижность клеток [20]. Киназы семейства SRC HCK, FRK и LYN являются онкогомологами PDGFRA/KIT, взаимодействуют как с PDGFRA, так и с-KIT в качестве нижестоящих эффекторов и играют критическую роль в пролиферации и выживании опухолевых клеток. Например, избыточная экспрессия LYN приводит к B-клеточной хронической лимфоцитарной лейкемии [21]. Известно, что LYN действует ниже по цепочке от нескольких участников сигнальных путей, таких как EPOR, KIT, MPL, хемокиновый рецептор CXCR4, а также от рецепторов интерлейкина 3 (ИЛ-3), ИЛ-5 и CSF2. Также опосредует фосфорилирование слитного белка BCR-ABL и KIT, регулирует активность фосфатидилинозитол-3-киназы и активацию АКТ1 и сигнального каскада МАРК (митоген-активируемой протеинкиназы) (рис. 2) [22].

M. Iida и соавт. исследовали, какая SRC-киназа опосредует ядерную транслокацию (рецептор эпидермального фактора роста) (EGFR) в устойчивых к цетуксимабу клетках рака легкого. EGFR является центральным регулятором прогрессирования опухоли при раке легкого у человека. Цетуксимаб представляет собой анти-EGFR-терапевтическое антитело. Анализы экспрессии мРНК и белка показали повышаюшую регуляцию членов семейства SRC-киназ Yes и LYN во всех клеточных клонах, а анализ иммунопреципитации - что EGFR взаимодействует с Yеs и LYN в устойчивых к цетуксимабу клонах, но не в исходных чувствительных клетках. При этом выключение экспрессии данных киназ приводило к нарушению перемешения EGFR в ядро. И наоборот, повышенная экспрессия Yes или LYN в родительских клетках с низкой экспрессией EGFR вызывала увеличение количества EGFR в ядре. Эти результаты демонстрируют, что названные киназы фосфорилируют EGFR по аминокислотному остатку Y1101, который влияет на ядерную транслокацию EGFR в этой модели устойчивости к цетуксимабу [23].

Киназа LYN влияет на ER $\alpha$, усиливая его экспрессию. Известно также, что LYN увеличивает клеточную пролиферацию в клеточных линиях РМЖ посредством связывания и фосфорилирования EGFR в цитоплазме и сопровождает его перемещение в ядро, благодаря чему LYN действует как фактор транскрипции в повышении экспрессии циклина D1, индуцибельной синтазы оксида азота (iNOS) и других проонкогенных факторов [24].

Киназа LYN гиперэкспрессирована при трижды негативном РМЖ. В ходе изучения механизмов этого явления было показано, что LYN является нижестоящим эффектором рецептора КIT в нормальных 


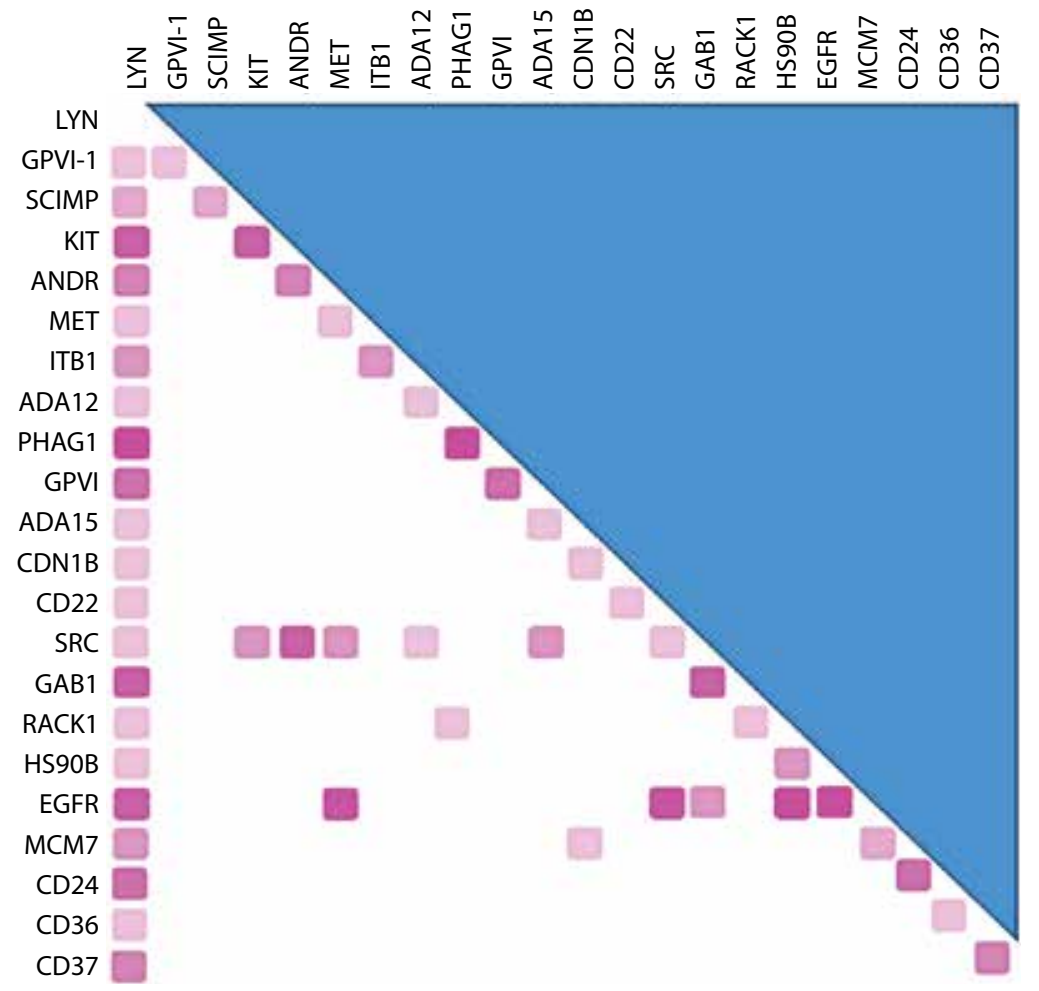

$>50$ публикаций о взаимодействии белков в базе UniProt/>50 publications on the interaction of proteins in the UniProt database

$>10$ публикаций о взаимодействии белков в базе UniProt/>10 publications on the interaction of proteins in the UniProt database

$>3$ публикаций о взаимодействии белков в базе UniProt/>3 publications on the interaction of proteins in the UniProt database

Рис. 2. Схема бинарного взаимодействия киназы LYN с белками в клетке. GPVI-1 - мембранный белок тромбоцитов; SCIMP - трансмембранный адаптерный белок; КIT - белковая рецепторная тирозинкиназа; ITB1 - интегрин бета-1; ADA12 - металлопротеиназа ADAM12; PHAG1 - фосфопротеин, ассоциированный со сфинголипидами; ADA15 - металлопротеиназа ADAM15; CDN1B - циклинзависимая киназа B1; CD22 - мембранный белок-рецептор B-лимфоцитов; SRC - семейство src-киназ; GAB1 - адаптерный белок; RACK1 - рецептор для активированной C киназы 1; HS90B - белок теплового шока 90; EGFR - белок семейства рецепторов эпидермального фактора роста; MCM7 - репликативный фактор МСM7; CD24 - гликопротеин, экспрессирующийся на поверхности В-лимфоцитов; CD36 - лейкоцитарный антиген CD36; CD37 - лейкоцитарный антиген $C D 37$

Fig. 2. Binary interaction of LYN kinase with cell proteins. Color intensity indicates the number of publications on proteins' interaction. Scheme of binary interaction of LYN kinase with proteins in the cell. GPVI-1 - platelet membrane protein; SCIMP - transmembrane adapter protein; KIT - protein receptor tyrosine kinase; ITB1 - integrin beta-1; ADA12 - metalloproteinase ADAM12; PHAG1 - phosphoprotein associated with sphingolipids; ADA15 metalloproteinase ADAM15; CDN1B - cyclin-dependent kinase B1; CD22 - membrane B-lymphocyte receptor protein; SRC - Src kinase family; GAB1 adapter protein; RACK1 - receptor for activated C kinase 1; HS90B - heat shock protein 90; EGFR is a protein of the epidermal growth factor receptor family; MCM7 - zeplicative factor MCM7; CD24 - glycoprotein expressed on the surface of B-lymphocytes; CD36 - leukocyte antigen CD36; CD37 - leukocyte antigen $C D 37$

клетках молочной железы [25]. При этом потеря функции белка BRCA1 гиперактивирует данную киназу. Полноразмерная изоформа LYN способствует инвазии опухолевых клеток. Продолжительность жизни пациентов с РМЖ с высоким соотношением изоформ LYN A/В меньше. Результаты экспериментов демонстрируют двойные механизмы стимулирования активности данной киназы при агрессивных формах РМЖ. Понимание этих механизмов имеет терапевтический потенциал, так как соотношение форм LYN A/B является биомаркером идентификации пациентов для ТT.

Киназа LYN входит в прогностически значимый набор генов для ER $\alpha$-позитивного РМЖ. Высокий уровень его экспрессии соотносится с неблагоприятным прогнозом. LYN и некоторые другие белки сигнального пути STAT3 являются терапевтическими мишенями для дальнейшего изучения, основанного на степени дифференциальной экспрессии [26].

Белки STAT, особенно STAT3, имеют решающее значение для путей, лежащих в основе опухоль-опо- средованного воспаления. Постоянная активация STAT3 при различных онкологических заболеваниях человека увеличивает пролиферацию опухолевых клеток, выживаемость, ангиогенез и метастазирование. Также конститутивно активированный STAT3 был обнаружен в раковых клетках шейки матки. Интерлейкин 6 (ИЛ-6) является центральным провоспалительным цитокином, вовлеченным в инфекцию женских половых органов. Он широко распространен в микроокружении рака шейки матки и важен в процессе канцерогенеза. Также ИЛ-6 является одним из ключевых активаторов STAT3 и может влиять на экспрессию LYN, которая, в свою очередь, способствует метастазированию клеток рака шейки матки посредством активации пути IL-6/STAT3. Пониженная или повышенная экспрессия LYN блокировала или активировала передачу сигналов по пути ИЛ-6/STAT3. STAT3 может напрямую взаимодействовать с LYN, способствуя метастазированию клеток рака шейки матки посредством активации пути ИЛ-6/STAT3 [4]. Первым 
этапом метастазирования рака является инвазия в окружающие ткани. Ключевым моментом проникновения в клетку и ее миграции служит цитоскелетная реорганизация. В эукариотических клетках миграция клеток требует формирования дополнительных актиновых филаментов. LYN может регулировать миграцию и инвазию клеток путем индуцированного ремоделирования F-актина [4].

Клаудин-2 усиливает метастазирование РМЖ и способствует развитию колоректального рака. Нокдаун отдельных членов киназ семейства SRC показывает, что снижение экспрессии Yes или Fуn усиливает экспрессию клаудина-2, тогда как пониженный уровень LYN уменьшает ее в клетках РМЖ. При колоректальном раке уровень клаудина-2 повышен. Его экспрессия может быть обнаружена при предопухолевых состояниях, таких как воспалительные заболевания кишечника, которые предрасполагают к образованию рака толстой кишки, а активация SRC коррелирует с худшим течением заболевания у пациентов с различными типами злокачественных опухолей. Было показано, что путь EGFR-MEK-ERK1/2 может регулировать транскрипцию CLDN2 в клетках аденокарциномы легкого A549. В этих клетках активация пути EGFR приводила к усилению связывания транскрипционных факторов c-Fos и c-Jun с промоторной областью человеческого CLDN2 через сайт связывания AP-1. Эти данные демонстрируют, что транскрипция клаудина-2 может регулироваться посредством пути SFK-c-Fos [27].

В другом исследовании было установлено, что LYN является ключевым узлом нескольких значимых биологических сетей, что предполагает его тесную связь с возникновением и прогрессированием рака пищевода. Сравнение паттернов экспрессии генов нормальных образцов пищевода, аденокарциномы пищевода и образцов клеток пищевода Барретта показало, что ключевым модулем в сигнальных взаимодействиях является ген $L Y N$. Кроме того, этот ген был гиперэкспрессирован в образцах как рака, так и пищевода Баррета, который является предраковым состоянием. Согласно результатам этого исследования, повышенная экспрессия гена $L Y N$ указывает на то, что он выполняет важную функцию как на ранних, так и на поздних стадиях патогенеза аденокарциномы пищевода. Это усиливает биологическое значение данного гена в механизмах развития и прогрессирования рака пищевода [28].

В исследовании методом анализа микрочипов определили список генов и путей, которые могут быть вовлечены в патогенез синдрома поликистозных яичников (СПКЯ). Биоинформационный анализ показал, что в образцах СПКЯ повышен уровень экспрессии $L Y N$ относительно нормальных образцов. Это также было подтверждено результатами полимеразной цепной реакции (ПЦР). Анализ сигнальных путей продемонстрировал, что $L Y N$ был значительно обогащен в CXCR4-опосредованных передачах сигналов и хемокин-опосредованных событиях. В нормальных условиях киназы семейства SRC необходимы, в том числе для механизмов воспалительных процессов. Нарушение регуляции белка LYN может участвовать в воспалении, связанном с СПКЯ, которое является важным механизмом, лежащим в основе резистентности к инсулину, часто встречающейся у пациентов с данной патологией. Также было высказано предположение, что дисрегуляция генов у пациентов с инсулинорезистентностью и без нее может играть большую роль в метаболических нарушениях и задержке роста фолликулов [29].

Результаты следующего исследования показали, что все пациенты с хроническим эозинофильным лейкозом и экспрессией онкогена FIP1L1-PDGFRA имеют более высокий уровень фосфорилированной киназы LYN. Она может фосфорилировать рецептор ИЛ-5а. Ингибирование LYN в FIP1L1-PDGFRA-положительных клетках хронического эозинофильного лейкоза снижает клеточную пролиферацию, индуцирует апоптоз и блокирует миграцию клеток [30]. Таким образом, гиперэкспрессия LYN ассоциирована со злокачественным фенотипом клеток эозинофильного лейкоза, что дает возможность проведения альтернативной терапии ингибиторами вышестоящих по сигнальным путям белков.

В $70 \%$ случаев развитие РМЖ зависит от экспрессии $\mathrm{ER} \alpha$ и связанного с ним пути передачи сигнала, а в $20 \%$ - от статуса HER2/ERBB2. Обнаруживаются все новые участники сигнальных путей ER $\alpha$. Например, NFIB и YBX1 представляют собой транскрипционные факторы, связанные с прогрессированием ER $\alpha$-негативного рака. В недавнем исследовании T.M. Campbell и соавт. было показано, что они также взаимодействуют с ER $\alpha$ - ключевым драйвером люминального ER $\alpha$ позитивного РМЖ [31]. Примечательно, что они оба взаимодействуют с комплексом ESR1-FOXA1 и подавляют активность $\mathrm{ER} \alpha$.

Белок GREB1 является ER $\alpha$-регулируемым белком, который может опосредовать действие эстрогена. Выключение GREB1 предотвращает гормональную пролиферацию нескольких клеточных линий РМЖ и предстательной железы и увеличивает продолжительность жизни мышей, которым имплантированы клетки рака яичника. Это может быть связано с ингибированием пролиферации и стимуляцией эпителиальной морфологии посредством снижения содержания субъединицы 2 коллагена типа I [32]. Таргетная терапия, направленная на белок GREB1, может ингибировать сигнальные пути, стимулирующие развитие опухолевых клеток, как ниже по ER $\alpha$-цепи взаимодействий, так и независимо от нее.

Известно, что заместительная гормональная терапия с использованием эстрогенов при менопаузе является общепризнанным фактором риска развития рака яичника, но есть мало сведений о том, как эстроген может 
способствовать возникновению этого заболевания на клеточном уровне. При исследовании этой проблемы канадские ученые определили, что хемокиновый рецептор CXCR7/ACKR3 чувствителен к эстрогену, так как экспрессия этого рецептора заметно усиливается эстрогеном посредством прямого вовлечения молекулы ER $\alpha$ и активации транскрипции в клетках рака яичников [33]. Экспрессия CXCR7 заметно повышалась при обработке эстрогеном клеток рака яичников. Эти данные подтверждают механизм прямой связи, который поддерживает активацию комплекса CXCR7/ CXCL11 под контролем ER $\alpha$, что ведет к индукции ЭМП и метастатическому поведению опухолевых клеток.

Эстрогеновый рецептор также оказывается вовлечен в сигнальный путь фосфоинозитид-3-киназы (РI3K), регуляция которого часто нарушается при злокачественных новообразованиях. В масштабном исследовании 60911 образцов солидных опухолей с помощью секвенирования нового поколения [34] мутации в генах, связанных с сигнальным путем РІ3К, были обнаружены в $44 \%$ случаев. При этом сочетание изменений в гене $E S R 1$ и/или в андрогеновом рецепторе (AR) с изменениями в пути РI3K было статистически значимым при раке мочевого пузыря, ободочной и прямой кишки, матки, простаты и первичном раке из неизвестного очага. Такой корреляции не наблюдается для образцов РМЖ, хотя мутации в этом гене часто вовлечены в механизм возникновения приобретенной устойчивости к эндокринной терапии. Эти данные предполагают, что существуют различные пути приобретения резистентности в зависимости от типов опухолей, что дает исследователям новые мишени для ТТ и варианты дизайна клинических испытаний.

\section{LYN И ERa КАК МИШЕНИ ТЕРАПИИ И ПРИЧИНА} РЕЗИСТЕНТНОСТИ К НЕЙ

Наиболее часто используемым препаратом для подавления экспрессии LYN является мультитаргетный низкомолекулярный ингибитор дазатиниб. Он ингибирует фосфорилирование SRC и LYN и нижестоящего субстрата киназы фокальной адгезии (FAK) в гормоночувствительных и гормонорефрактерных клеточных линиях [35]. Было показано, что SRC и ER $\alpha$ взаимодействуют на клеточной мембране в комплексе с PELP-1 и PI3K, что приводит к активации путей ERK1/2 и AKT. Взаимодействие $\mathrm{ER} \alpha$ и SRC, приводящее к фосфорилированию $\mathrm{ER} \alpha$ по тирозину 537, способствует ядерному экспорту. Ингибирование SRC сводит на нет этот эффект, вызывая секвестирование ER $\alpha$ в ядре [36]. SRCкиназы регулируются фосфорилированием 2 остатков тирозина, которые имеют противоположные эффекты. Тирозин 416 в петле активации киназного домена SRC увеличивает активность фермента, в то время как фосфорилирование тирозина 527 с помощью CSK (C-концевой SRC-киназы) снижает активность фермента. Известно, что дазатиниб воздействует на оба фосфорилированных сайта [37]. Этот препарат значительно ингибирует инвазию и индуцирует апоптоз клеток, но меньше влияет на клеточный цикл. Клеточные линии с высокой экспрессией Yes, LYN, Eph²A, кавеолина-1 и -2, мезина, аннексина-1 и uPA (урокиназа) особенно чувствительны к дазатинибу [38]. Другими ингибиторами SRC являются KX2-391, бозутиниб и саракатиниб. Эти препараты обладают противоопухолевой активностью и используются для терапии онкологических заболеваний.

При лечении трижды негативного РМЖ клинически эффективными оказались препараты, опосредованно действующие на онкоген МYС, в том числе ингибиторы АKT/PI3K-пути и дазатиниб (за счет воздействия на киназу LYN). Исследования демонстрируют, что МҮС является важной терапевтической мишенью для онкогенеза рака. Однако специфические низкомолекулярные ингибиторы данного онкогена пока не имеют достаточной эффективности в клинической терапии. Следовательно, существует потребность в косвенном воздействии на МYС через других участников сигнальных путей. В их качестве рассматриваются циклинзависимые киназы (CDK1), киназы Aurora B и SUMO-активирующие киназы. Известно, что клетки РМЖ с высокой экспрессией МҮС реагируют на дазатиниб. Киназа LYN является прямой мишенью этого препарата, важна для активации В-клеток и активна при раке простаты и РМЖ. Экспрессия мутантной формы LYN (T319I) делает клеточные линии нечувствительными к дазатинибу. Пациенты с высокой экспрессией LYN были более склонны к рецидивам и имели низкие показатели выживаемости. При этом у больных с низкими значениями МҮС экспрессия LYN не коррелировала с выживаемостью. Предполагается, что гиперактивность МҮС приводит к усилению зависимости от LYN при РMЖ [2].

Эстрогены влияют на многие физиологические процессы и могут участвовать в развитии или прогрессировании заболеваний, включая онкологические, в первую очередь РМЖ. Эстрогенный сигнал передается через рецепторы эстрогена, которые имеют двойную локализацию: содержатся внутри клеток и в плазматической мембране. После связывания лиганда мембранный рецептор активирует различные сигнальные пути, индуцируя нижестоящие факторы транскрипции [39]. Механизм эстроген-индуцированного канцерогенеза и факторы, усиливающие генотоксический компонент в общем действии эстрогенов, в том числе в случае возрастной патологии [40], очень важны, поскольку могут влиять на тип канцерогенеза и свойства развивающихся гормонозависимых опухолей [41].

При РМЖ обычно экспрессируется ER $\alpha$-регулируемый транскрипционный фактор. ER $\alpha$-позитивный РМЖ обычно хорошо реагирует на терапию, которая ослабляет передачу сигналов $\mathrm{ER} \alpha$, либо блокируя выработку эстрогенов через ингибиторы ароматазы, 
근 либо антагонизируя активность эстрогенов посредст- вом конкурентного связывания антагонистов $\mathrm{ER} \alpha$, $\sim$ таких как тамоксифен [42].

В течение последних двух десятилетий ингибиторы ароматазы 3-го поколения, такие как анастрозол, летрозол и эксеместан, стали стандартным гормональным методом лечения пациентов с РМЖ как при поздних, так и при ранних стадиях заболевания. После появления резистентности к терапии можно назначать прием другого эндокринного агента (например, фулвестранта), использовать селективный модулятор ER $\alpha$ (например, тамоксифен) или аддитивные гормональные препараты, такие как прогестины (ацетат медроксипрогестерона) и эстрогены (этинилэстрадиол) [43] (рис. 3).

Также при развитии резистентности к гормональной терапии РМЖ применяются комбинации гормональных препаратов с таргетными ингибиторами. Данные некоторых клинических исследований в этой области представлены в таблице. Сочетание ингибирования SRC-киназ с ингибиторами ароматазы [44, 45] и фулвестрантом [46, 47] увеличивает эффективность лечения у некоторых подгрупп пациентов с РМЖ. Да- затиниб и бортезомиб отчасти вызывают ресенсибилизацию к гормональным препаратам при комбинированной терапии [47, 48]. Вероятно, необходима разработка дополнительных молекулярных способов отбора пациентов в подгруппы для назначения комбинированных вариантов лечения.

Молекулярная диагностика опухолей, направленная на определение дефектов в генах, ассоциированных с сигнальными путями, может выявлять устойчивость к терапии. Однако в случае лечения, направленного на LYN, мутации редко являются причиной резистентности. Секвенирование Р-петли и сегмента активации киназного домена LYN из геномной ДНК 5 клеточных линий мезенхимального РМЖ и 50 опухолей молочной железы не выявило соматических мутаций. Также не была обнаружена амплификация ДНК в линиях или опухолях РМЖ. Избыточная экспрессия/активность LYN, скорее всего, контролируется в основном вышестоящими регуляторами [9] и регулирует нижестоящие процессы. Например, гиперэкспрессия LYN при трижды негативном РМЖ ассоциирована с потерей функции белка BRCA1 [24]. В случае хронического миелолейкоза гиперэкспрессия LYN может привести

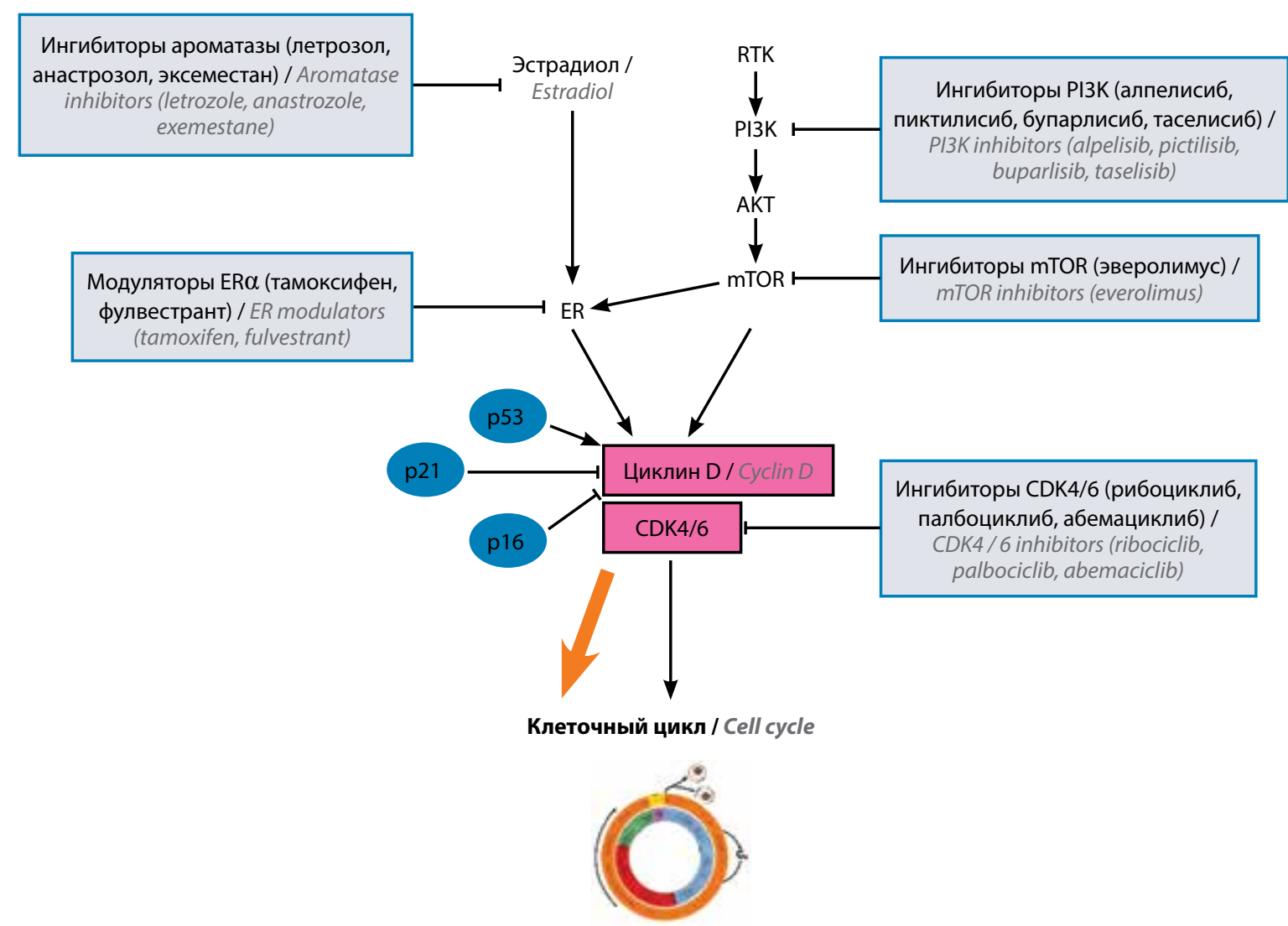

Рис. 3. Действие препаратов для лечения рака молочной железы на мишени сигнальных путей клетки. ER - эстрогеновый рецептор; RTK - рецепторная тирозинкиназа; PI3K - фосфатидилинозитол-3-киназа; AKT -внутриклеточная протеинкиназа; тTOR - мишень рапамицина; CDK4/6 - циклинзависимые киназы 4/6; p53 - транскрипционный фактор, регулирующий клеточный цикл; р21 - внутриклеточный белок-ингибитор циклинзависимой киназы; р16-белок-регулятор клеточного цикла

Fig. 3. The way drugs used to treat breast cancer affect target of cell signaling pathways. ER - estrogen receptor; RTK - receptor tyrosine kinase; PI3K phosphatidylinositol-3-kinase; AKT -intracellular protein kinase; mTOR - mammalian target of rapamycin; CDK4/6 - cyclin-dependent kinases 4/6; p53 - transcription factor regulating the cell cycle; p21 - intracellular protein inhibitor of cyclin-dependent kinases; $p 16$ - a protein regulator of the cell cycle 
Результаты клинических исследований комбинаций гормональных и таргетных препаратов для лечения рака молочной железы

Results of clinical trials of combinations of hormonal and targeted drugs for the treatment of breast cancer

\begin{tabular}{|c|c|c|c|}
\hline $\begin{array}{c}\text { Номер } \\
\text { исследования } \\
\text { Identifier }\end{array}$ & $\begin{array}{l}\text { Препараты } \\
\text { Drugs }\end{array}$ & $\begin{array}{l}\text { Статус } \\
\text { Status }\end{array}$ & $\begin{array}{c}\text { Результат исследования } \\
\text { Study results }\end{array}$ \\
\hline NCT00767520 & $\begin{array}{c}\text { Дазатиниб + } \\
\text { эксеместан } \\
\text { Dasatinib + } \\
\text { Exemestane }\end{array}$ & $\begin{array}{c}\text { Завершено } \\
28.02 .2013 \\
\text { Completed } \\
28.02 .2013\end{array}$ & $\begin{array}{c}\text { Различия по показателям беспрогрессивной выживаемости не были } \\
\text { значимыми в общей популяции исследования, но более высокие } \\
\text { показатели частоты клинической эффективности в группе дазатиниба } \\
\text { и выживаемости без прогрессирования у пациентов с метастатической } \\
\text { стадией позволяют предположить, что дазатиниб имеет эффективность } \\
\text { в определенных подгруппах } \\
\text { Progression-free survival difference was not significant in overall study population, } \\
\text { but higher clinical benefit rate in the dasatinib arm and higher progression-free survival } \\
\text { in patients with symptomatic bone metastasis suggests that dasatinib has efficacy in a subset }\end{array}$ \\
\hline NCT00903006 & $\begin{array}{c}\text { Дазатиниб + } \\
\text { фулвестрант, } \\
\text { дазатиниб + } \\
\text { далотузумаб } \\
\text { Dasatinib + } \\
\text { fulvestrant, } \\
\text { dasatinib + } \\
\text { dalotuzumab }\end{array}$ & $\begin{array}{c}\text { Прекращено } \\
02.02 .2015 \\
\text { Terminated } \\
02.02 .2015\end{array}$ & $\begin{array}{c}\text { Комбинация фулвестранта и дазатиниба была эффективнее, чем дало- } \\
\text { тузумаба и дазатиниба в испытаниях in vitro. Исследование с участием } \\
\text { пациентов прекращено досрочно в связи с малым количеством участников } \\
\text { The combination of fulvestrant and dasatinib was more effective than dalotuzumab } \\
\text { and dasatinib in in vitro trials. The study involving patients was terminated prematurely due } \\
\text { to the small number of participants }\end{array}$ \\
\hline NCT00754325 & $\begin{array}{c}\text { Дазатиниб + } \\
\text { фулвестрант } \\
\text { Dasatinib + } \\
\text { fulvestrant }\end{array}$ & $\begin{array}{c}\text { Завершено } \\
26.05 .2016 \\
\text { Completed } \\
26.05 .2016\end{array}$ & $\begin{array}{c}\text { Добавление дазатиниба к фулвестранту не улучшило клинических } \\
\text { показателей. Комбинация фулвестранта и дазатиниба } \\
\text { переносилась хорошо } \\
\text { The addition of dasatinib to fulvestrant did not improve clinical performance. } \\
\text { The combination of fulvestrant and dasatinib was well tolerated }\end{array}$ \\
\hline NCT00696072 & $\begin{array}{c}\text { Дазатиниб + } \\
\text { летрозол } \\
\text { Dasatinib + } \\
\text { letrozole }\end{array}$ & $\begin{array}{c}\text { Завершено } \\
13.06 .2016 \\
\text { Completed } \\
13.06 .2016\end{array}$ & $\begin{array}{c}\text { Улучшение клинических показателей наблюдалось у } 71 \% \text { пациентов. } \\
\text { Средняя выживаемость без прогрессирования при приеме летрозола } \\
\text { и дазатиниба составила } 20 \text { мес } \\
\text { Improvement of clinical indicators was observed in } 71 \% \text { of patients. The average } \\
\text { progression-free survival with letrozole and dasatinib was } 20 \text { months }\end{array}$ \\
\hline NCT01142401 & $\begin{array}{c}\text { Бортезомиб + } \\
\text { фулвестрант } \\
\text { Bortezomib + } \\
\text { fulvestrant }\end{array}$ & $\begin{array}{l}\text { Активно } \\
\text { Active }\end{array}$ & $\begin{array}{c}\text { Бортезомиб, вероятно, повышает эффективность фулвестранта } \\
\text { при резистентности к ингибиторам ароматазы за счет снижения } \\
\text { приобретенной устойчивости } \\
\text { Bortezomib likely enhances the effectiveness of fulvestrant in AI-resistant metastatic breast } \\
\text { cancer by reducing acquired resistance }\end{array}$ \\
\hline
\end{tabular}

к резистентности путем регуляции образования белковых комплексов BCR-ABL через сигнальный путь LYN/BCR-ABL/SIRT1, что, в свою очередь, влияет на экспрессию Ac-Foxо1 и р53, уменьшая апоптоз и опосредуя устойчивость к иматинибу [49].

Приблизительно в 75 \% случаев РМЖ поддается лечению с помощью гормональной терапии, но зачастую у пациентов развивается резистентность. Длительное воздействие антиэстрогенов заставляет клетки РМЖ адаптироваться и изменять свои свойства. Это многоаспектная проблема, поскольку в данном процессе задействовано множество сигнальных путей вследствие комбинированных изменений негеномных или геномных эффектов [50]. В ходе этого эволюционного процесса в опухоли увеличивается активность ароматазы и МАРК [51]. Путь МАРК частично участвует в адаптивном процессе, способствует фосфорилированию $\mathrm{ER} \alpha$ (и следовательно, его активации) и приводит к усиленному синтезу ДНК и пролиферации клеток в отсутствие экзогенного эстрогена [52].
Помимо этого, с процессом адаптации связаны еще несколько механизмов, в том числе:

- изменения в активации сигнальных путей AKT/ PI3K и рапамицинового фактора роста млекопитающих (mTOR) [53] (уровень экспрессии AKT (pS473) значимо выше в тамоксифен-резистентной группе по сравнению с тамоксифен-чувствительной [54]);

- гиперэкспрессия факторов роста семейства EGFR тирозинкиназ - уровень экспрессии EGFR значимо выше в тамоксифен-резистентной группе по сравнению с тамоксифен-чувствительной группой [54];

- высокий уровень экспрессии VEGFR-2, который также рассматривается в качестве маркера резистентности опухоли к тамоксифену [55];

- транскрипция тирозинкиназных рецепторов факторов роста (EGFR, HER2 и IGFR), что повышает активность их медиаторов и увеличивает пролиферацию клеток, и активация гипоксия-зависимых сигнальных путей (HIF-1/VEGF и Snail/ $\beta$-катенин) [56]. 
Предполагалось, что данные эффекты (снижение содержания ER $\alpha$, активность EGFR, IGFR) могут возникать в том числе вследствие развивающейся в опухолях гипоксии и разницы в стабильности данных факторов [56]. Параллельных аналогичных сигнальных путей всегда несколько, и активизация происходит в результате изменения действующих веществ: например, в случае метформина (подавляет ER $\alpha$ и $\mathrm{mTOR}$ ) происходит активация передачи сигналов AKT/Snaill [57].

Большую роль в возникновении гормональной резистентности играют также межклеточные механизмы передачи сигнала и эпигенетические факторы, например воздействие на соседние клетки путем межклеточных контактов [58] или паракринным путем, в том числе через продукцию клетками экзосом, содержащих метаболически активные белки и некоторые нуклеиновые кислоты, такие как микроРНК [59]. Короткие одноцепочечные РНК (микроРНК) участвуют в посттранскрипционной регуляции экспрессии различных генов. Искажение работы этой системы происходит в процессе злокачественной трансформации, а потом и терапии опухоли [60], и микроРНК могут служить биомаркерами устойчивости к лечению [61]. Другие эпигенетические механизмы модификации экспрессии гена ESR1 включают в себя гиперметилирование $\mathrm{CpG}$ (CpG-островки генома) в промоторах и повышенную активность гистондеацетилазы [62].

Мутации в гене ESR1, кодирующем ER $\alpha$, также негативно влияют на ответ на гормональную терапию. Было предположено, что устойчивость к тамоксифену является результатом выбора опухолевых клеток, которые распознают комплекс ER $\alpha /$ тамоксифен как агонистический. Однако в последнее время у пациентов с рецидивами метастазирования обнаружены мутации в лигандсвязывающем домене $\mathrm{ER} \alpha$ (25-40 \% случаев), хотя они очень редко встречаются у больных, не проходивших лечение [63]. Соматические мутации в ESR1 являются потенциальным механизмом вторичной эндокринной резистентности при РМЖ, тогда как при секвенировании ER $\alpha$-позитивных и $E R \alpha-$-нативных первичных опухолей молочной железы не были обнаружены мутации в гене ESR1. При недавно диагностированном нелеченом РМЖ мутации в ESR1 встречаются редко, но, по-видимому, они часто возникают во время прогрессирования резистентности к гормонам, особенно в контексте терапии эстрогенной депривацией. Мутации в кодонах лигандсвязывающего домена (LBD) в гене, кодирующем $\mathrm{ER} \alpha(E S R 1)$ (10$40 \%$ случаев), приводят к появлению лиганд-независимых конститутивно активных рецепторов. Кроме того, могут происходить хромосомные транслокации в районе $E S R 1$, приводящие к формированию слитных белков, которые лишены LBD и полностью невосприимчивы ко всем эндокринным методам лечения. Результаты исследований указывают на то, что N-концевые слияния ESR1 с участием экзонов 6-7 являются рецидивирующим фактором устойчивости к гормональной терапии и нечувствительны к $E R \alpha$-таргетной терапии. Важно, что все слияния ESR1 представляют собой результат точки разрыва в районе интрона 6 ESR1 и, следовательно, не имеют интактного LBD [64]. Две наиболее распространенных мутации - Y537S и D538G и химерный белок ESR1-YAP1 демонстрировали усиленные коактиваторные взаимодействия по сравнению с рецепторами ER $\alpha$ дикого типа. Ингибирование этих коактиваторов снижало способность мутантов ESR1 к активированию транскрипции и содествовало развитию РМЖ in vitro и in vivo. Таким образом, выявление коактиваторов, которые связываются с мутантными белками ER $\alpha$, поможет определить новые терапевтические мишени для эндокринно-резистентного рака [65]. У пациентов с мутантным аллелем Y537S могут быть худшие результаты по сравнению с пациентами, у которых в опухолях присутствует мутация D538G [66].

Носительство мутантного генотипа GG rs2228480 (Т594T) гена ESR1 ассоциировано с резистентностью к терапии тамоксифеном [67], особенно при люминальном подтипе В РМЖ [68]. Полагают, что данная мутация может способствовать нарушению сайтов связывания ER $\alpha$ для взаимодействия с коактиваторами. В результате образуется функционально неактивный рецептор, неспособный взаимодействовать с тамоксифеном [54].

Согласно исследованию пациентов с раком эндометрия, в 19 из 1034 (1,8\%) случаев опухолей имелись мутации в ESR1: 12 - в 537Y, 4 - в 538D и $3-$ в 536L. У больных с мутацией в данном гене отмечается значительно более низкий индекс массы тела по сравнению с больными без мутаций, но все пациенты имели сходные характеристики по возрасту, стадии и степени заболевания, а также по показателям беспрогрессивной выживаемости [69].

Ранее было показано, что соматические мутации в гене $E S R 1$ вовлечены в развитие устойчивости к гормональной терапии РМЖ тамоксифеном. Например, соматическая мутация Y537S была специфически связана с приобретенной эндокринной устойчивостью. В исследовании М. Fiorillo и соавт. [70] изучался молекулярный механизм этого явления. Культура клеток РМЖ MCF-7, трансдуцированная лентивирусным вектором, экспрессирующим молекулу ESR1 (Y537S), была функционально устойчива к тамоксифену. Дальнейшая фенотипическая характеристика клеток MCF-7-Y537S показала, что они демонстрируют повышенную устойчивость к апоптозу, вызванному данным препаратом. Анализ метаболизма этих клеток выявил гиперметаболический фенотип с усилением митохондриального дыхания и продукции аденозинтрифосфата, а также с усиленным аэробным гликолизом (рис. 4).

Также была обнаружена избирательная активация сигнального пути Rho-GDI/PTEN мутацией ER $\alpha$ Y537S. Кроме того, мутация Y537S специфически связана со сверхэкспрессией ряда белковых маркеров 


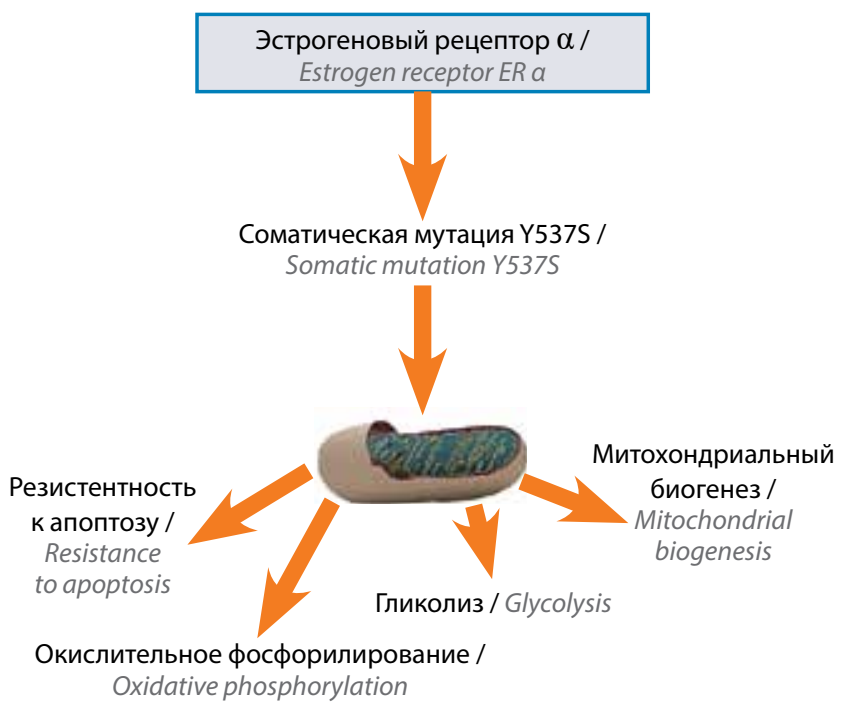

Рис. 4. Роль мутации Y537S эстрогенового рецептора ЕR $\alpha$ в развитии резистентности к тамоксифену

Fig. 4. The way Y537S mutation of estrogen receptor ER $\alpha$ affects development of tamoxifen resistance

неблагоприятного клинического прогноза (COL6A3, ERBB2, STAT3, AFP, TFF1, CDK4 и CD44). Таким образом, был обнаружен новый метаболический механизм, приводящий к эндокринной резистентности, который может иметь большое значения для улучшения результатов терапии.

В последнее время исследования с помощью высокопроизводительных технологий выявили в ER $\alpha$-позитивных образцах метастатического РМЖ большое количество молекулярных аберраций в других потенциальных генах-драйверах, таких как мутации в PIK3СA, амплификации FGFR1 и CCND1. Это привело к появлению нескольких методов лечения, нацеленных на данные пути, чтобы обойти или задержать развитие эндокринной резистентности [48].

Тамоксифен, входящий в группу селективных модуляторов эстрогеновых рецепторов (SERM), используется для долгосрочной адъювантной терапии при $\mathrm{ER} \alpha$-положительном РМЖ уже более 40 лет [71]. Новую группу составляют селективные ER $\alpha$-регуляторы (SERD), к которым относится фулвестрант. Они являются конкурентными антагонистами ER $\alpha$, вызывающими конформационный сдвиг рецептора, приводящий к убиквитинированию и последующей деградации $\mathrm{ER} \alpha$ через убиквитин-протеасомную систему. Уникальная двойная функция SERD (антагонизм и истощение $\mathrm{ER} \alpha$ ) может позволить им блокировать передачу сигналов $E R \alpha$ в клеточных условиях, где другие эндокринные агенты, такие как тамоксифен или ингибиторы ароматазы, не работают [72]. Другими широко применяемыми в клинической практике лечения гормонозависимого РМЖ препаратами являются ингибиторы ароматазы 3-го поколения эксеместан, летрозол и анастрозол.

Тамоксифен в целом хорошо переносится больными, но иногда может вызывать побочные эффекты (например, рак эндометрия или тромбоэмболические осложнения) из-за его частичной активности в качестве агониста эстрогенов. Согласно результатам ряда метаанализов, фулвестрант демонстрирует ряд преимуществ по сравнению с анастрозолом, эксеместаном, тамоксифеном и торемифеном [73] и лучше переносится пациентами. Первоначально он был одобрен как препарат 2-й линии, однако клинические исследования продемонстрировали, что его лучше использовать в качестве 1-й линии терапии. К недостаткам фулвестранта относятся плохая биологическая доступность и внутримышечная инъекционная доставка [74]. Наиболее распространенный подход для преодоления вторичной резистентности - смена режима гормональной терапии.

Мутантный белок ER $\alpha$ все еще может связывать антиэстрогены, такие как тамоксифен и фулвестрант, хотя для его ингибирования требуются более высокие дозы этих препаратов. Таргетная терапия в случае ESR1-мyтаций, возможно, будет ориентирована на геномные портреты каждого пациента. Существует потребность в разработке более сильных или специфических антагонистов мутантных форм для блокирования передачи сигналов $\mathrm{ER} \alpha$ в качестве селективных модуляторов $\mathrm{ER} \alpha$ следующего поколения, а также селективных ER $\alpha$ понижающих регуляторов [48].

Изучение мутантных аллель-специфических транскрипционных программ показывает, что они обогащены генами и путями, которые опосредуют передачу сигналов фактора роста и способствуют метастазированию. Эти результаты обеспечивают механистическую основу, на которой мутации ER $\alpha$ вызывают эндокринную резистентность, и могут объяснить склонность к развитию метастазов и низкие показатели общей выживаемости у пациентов с метастатическим РМЖ [75].

\section{ЗАКЛЮЧЕНИЕ}

В результате изучения участников взаимодействия проонкогенов обнаруживаются новые метаболические механизмы, приводящие к лекарственной резистентности, что может иметь большое значение для прогноза лечения и открытия новых мишеней для ТT.

На основе давно известного факта, что в результате адаптивных изменений в тканях опухолей во время длительного лечения тамоксифеном повышается чувствительность к эстрогену [50], разрабатываются синтетические селективные имитаторы эстрогена (SEM) BMI-135, TTC-352 [76], а также природный эстроген эстетрол [77], которые предлагается использовать в качестве более безопасных эстрогенных агентов по сравнению с 17ß-эстрадиолом для лечения эндокриннорезистентных РМЖ.

При развитии резистентности к гормональной терапии РМЖ применяется комбинация ингибиторов ароматазы с ингибиторами PI3K/AKT/mTOR/сигнального пути (эверолимус), а в случае HER2-положительных 
опухолей добавляется анти-HER2-таргетная терапия (трастузумаб) [74]. Комбинация ингибирования SRC с ингибиторами ароматазы [78] и фулвестрантом [79] снижает пролиферацию и метастазирование эндокринно-устойчивых клеточных линий РМЖ. Дазатиниб [36] и другие ингибиторы SRC [80] вызывают ресенсибилизацию к тамоксифену и фулвестранту, но только в определенных подгруппах пациентов.
В целом можно предположить, что ингибирование передачи дополнительных клеточных сигналов в сочетании с гормональной терапией поможет не допустить или задержать развитие гормональной резистентности. Также с появлением новых терапевтических подходов необходимо использовать дополнительные молекулярные способы отбора пациентов в подгруппы для назначения комбинированных вариантов терапии.

\section{Л И}

1. Bilal E., Alexe G., Yao M. et al. Identification of the YES1 kinase as a therapeutic target in basal-like breast cancers. Genes Cancer 2010;1(10):1063-73 DOI: $10.1177 / 1947601910395583$.

2. Martins M.M., Zhou A.Y. Corella A. et al. Linking tumor mutations to drug responses via a quantitative chemical-genetic interaction map. Cancer Discov 2015;5(2):154-67. DOI: $10.1158 / 2159-8290 . C D-14-0552$.

3. Шестакова Е.А. Мутации в генах эстрогенового рецептора $\alpha$ (ESR1) и киназы семейства SRC (LYN), accoциированные с резистентностью к гормонотерапии рака яичников. Успехи молекулярной онкологии 2021;8(1):10-6. [Shestakova E.A. Mutations in the genes of the estrogen receptor $\alpha$ (ESR1) and kinase of the SRC (LYN) family associated with resistance to hormone therapy for ovarian cancer. Uspekhi molekulyarnoy onkologii $=$ Advances in Molecular Oncology 2021;8(1):10-6. (In Russ.)]. DOI: 10.17650/2313-805X-2021-8-1-10-16.

4. Liu S., Hao X., Ouyang X. et al. Tyrosine kinase LYN is an oncotarget in human cervical cancer: a quantitative proteomic based study. Oncotarget 2016;7(46): 75468-81. DOI: 10.18632/oncotarget.12258.

5. Meade J., Fernandez C., Turner M. The tyrosine kinase Lyn is required for B cell development beyond the T1 stage in the spleen: rescue by over-expression of Bcl-2. Eur J Immunol 2002;32(4): 1029-34. DOI: 10.1002/15214141(200204)32:4<1029::AIDIMMU1029>3.0.CO;2-M.

6. Ingley E. Functions of the Lyn tyrosine kinase in health and disease. Cell Commun Signal 2012;10(1):21. DOI: $10.1186 / 1478-811 X-10-21$.

7. Кит О.И., Водолажский Д.И., Кутилин Д.С. и др. Транскриптомная активность эстроген-регуляторных генов при малигнизации тканей тела матки. Политематический сетевой электронный научный журнал Кубанского государственного аграрного уни- верситета 2016;115:294-304. [Kit O.I., Vodolazhsky D.I, Kutilin D.S. et al. Transcriptomic activity of estrogenregulatory genes in malignancy uterine tissues. Politematicheskij setevoj elektronnyj nauchnyj zhurnal Kubanskogo gosudarstvennogo agrarnogo universiteta $=$ Scientific Journal of the Kuban State Agrarian University 2016;115:294-304. (In Russ.)].

8. Summy J.M., Gallick G.E. Src family kinases in tumor progression and metastasis Cancer Metastasis Rev 2003;22(4):337-58.

DOI: 10.1023/a:1023772912750.

9. Choi Y.L., Bocanegra M., Kwon M.J. et al. LYN is a mediator of epithelialmesenchymal transition and a target of dasatinib in breast cancer. Cancer Res 2010;70(6):2296-306.

DOI: 10.1158/0008-5472.CAN-09-3141.

10. Dressman H.K., Berchuck A., Chan G. et al. An integrated genomic-based approach to individualized treatment of patients with advanced-stage ovarian cancer J Clin Oncol 2007;25(5):517-25. DOI: 10.1200/JCO.2006.06.3743.

11. Roseweir A.K., Qayyum T., Lim Z. et al. Nuclear expression of Lyn, a Src family kinase member, is associated with poor prognosis in renal cancer patients. BMC Cancer 2016;16:229.

DOI: 10.1186/s12885-016-2254-9.

12. Wu J., Meng F., Lu H. et al. Lyn regulates BCR-ABL and Gab2 tyrosine phosphorylation and c-Cbl protein stability in imatinib-resistant chronic myelogenous leukemia cells. Blood 2008;111(7):3821-9. DOI: 10.1182/blood-2007-08-109330.

13. Su N., Peng L., Xia B. et al. Lyn is involved in CD24-induced ERK1/2 activation in colorectal cancer. Mol Cancer 2012;11:43. DOI: 10.1186/1476-4598-11-43.

14. Zardan A., Nip K.M., Thaper D. et al. Lyn tyrosine kinase regulates androgen receptor expression and activity in castrate-resistant prostate cancer. Oncogenesis 2014;3(8):e115. DOI: 10.1038 /oncsis. 2014.30.

15. Mello A.A., Leal M.F., Rey J.A. et al. Deregulated Expression of SRC, LYN and
CKB kinases by DNA methylation and its potential role in gastric Cancer invasiveness and metastasis. PLoS One 2015; 10(10):e0140492.

DOI: 10.1371/journal.pone.0140492.

16. Yang S.Y.C., Lheureux S., Karakasis K. et al. Landscape of genomic alterations in high-grade serous ovarian cancer from exceptional long- and short-term survivors. Genome Med 2018;10(1):81. DOI: 10.1186/s13073-018-0590-x.

17. Zhang K., Kong X., Feng G. et al. Investigation of hypoxia networks in ovarian cancer via bioinformatics analysis. J Ovarian Res 2018;11(1):16. DOI: 10.1186/s13048-018-0388-X.

18. Koussounadis A., Langdon S.P., Um I. et al. Dynamic modulation of phosphoprotein expression in ovarian cancer xenograft models. BMC Cancer 2016; 16:205. DOI: 10.1186/s12885-016-2212-6.

19. Bromann P.A., Korkaya H., Courtneidge S.A The interplay between Src family kinases and receptor tyrosine kinases. Oncogene 2004;23(48):7957-68.

DOI: $10.1038 /$ sj.onc. 1208079 .

20. Yeatman T.J. A renaissance for SRC. Nat Rev Cancer 2004;4(6):470-80. DOI: $10.1038 / \mathrm{nrc} 1366$.

21. Chen W., Li Y., Wang Z. Evolution of oncogenic signatures of mutation hotspots in tyrosine kinases supports the atavistic hypothesis of cancer. Sci Rep 2018;8(1):8256. DOI: 10.1038/s41598-018-26653-5.

22. Liang X., Wisniewski D., Strife A. et al. Phosphatidylinositol 3-kinase and Src family kinases are required for phosphorylation and membrane recruitment of Dok-1 in c-Kit signaling. J Biol Chem 2002;277(16):13732-8. DOI: 10.1074/jbc.M200277200.

23. Iida M., Brand T.M., Campbell D.A. et al. Yes and Lyn play a role in nuclear translocation of the epidermal growth factor receptor. Oncogene 2019;3893: 2435. DOI: 10.1038/s41388-018-0572-X.

24. Tatosyan A.G., Mizenina O.A. Kinases of the Src family: structure and functions. Biochemistry (Mosc) 2000;65(1):49-58. 
25. Tornillo G., Knowlson C., Kendrick H. et al. Dual Mechanisms of LYN kinase dysregulation drive aggressive behavior in breast cancer cells. Cell Rep 2018;25(13):3674-92.e10. DOI: 10.1016/j.celrep.2018.11.103.

26. Liu L.Y., Chang L.Y., Kuo W.H. et al. Prognostic features of signal transducer and activator of transcription 3 in an $\mathrm{ER}(+)$ breast cancer model system Cancer Inform 2014;13:21-45. DOI: $10.4137 /$ CIN.S12493.

27. Tabariès S., Annis M.G., Hsu B.E. et al. Lyn modulates Claudin-2 expression and is a therapeutic target for breast cancer liver metastasis. Oncotarget 2015;6(11):9476-87. DOI: 10.18632/oncotarget.3269.

28. Liu D. LYN, a key gene from bioinformatics analysis, contributes to development and progression of esophageal adenocarcinoma. Med Sci Monit Basic Res 2015;21:253-61. DOI: 10.12659/MSMBR.895463.

29. Shen H., Liang Z., Zheng S., Li X. Pathway and network-based analysis of genome-wide association studies and RT-PCR validation in polycystic ovary syndrome. Int J Mol Med 2017;40(5): 1385-96. DOI: 10.3892/ijmm.2017.3146.

30. Li B., Zhang G., Li C. et al. Lyn mediates FIP1L1-PDGFRA signal pathway facilitating IL-5RA intracellular signal through FIP1L1-PDGFRA/JAK2/Lyn/ AKT network complex in CEL. Oncotarget 2016;8(39):64984-98. DOI: 10.18632 /oncotarget.11401.

31. Campbell T.M., Castro M.A.A., de Oliveira K.G. et al. ER $\alpha$ binding by transcription factors NFIB and YBX1 enables FGFR2 signaling to modulate estrogen responsiveness in breast cancer. Cancer Res 2018;78(2):410-21. DOI: 10.1158/0008-5472.CAN-17-1153.

32. Hodgkinson K., Forrest L.A., Vuong N. et al. GREB1 is an estrogen receptorregulated tumour promoter that is frequently expressed in ovarian cancer. Oncogene 2018;37(44):5873-86. DOI: $10.1038 / \mathrm{s} 41388-018-0377-\mathrm{y}$.

33. Benhadjeba S., Edjekouane L., Sauvé K. et al. Feedback control of the CXCR7/ CXCL11 chemokine axis by estrogen receptor $\alpha$ in ovarian cancer. Mol Oncol 2018;12(10):1689-705. DOI: $10.1002 / 1878-0261.12362$.

34. Millis S.Z., Jardim D.L., Albacker L. et al. Phosphatidylinositol 3-kinase pathway genomic alterations in 60,991 diverse solid tumors informs targeted therapy opportunities. Cancer 2019;125(7):1185-99. DOI: $10.1002 /$ cncr.31921.

35. Tatarov O., Mitchell T.J., Seywright M. et al. SRC family kinase activity is upregulated in hormone-refractory prostate cancer. Clin Cancer Res 2009;15(10):3540-9. DOI: 10.1158/1078-0432.CCR-08-185.
36. Guest S.K., Ribas R., Pancholi S. et al. Src is a potential therapeutic target in endocrine-resistant breast cancer exhibiting low estrogen receptor-mediated transactivation. PLoS One 2016;11(6):e0157397. DOI: 10.1371/journal.pone.0157397.

37. Caccia D., Miccichè F., Cassinelli G. et al. Dasatinib reduces FAK phosphorylation increasing the effects of RPI-1 inhibition in a RET/PTC1-expressing cell line. Mol Cancer 2010;9:278. DOI: 10.1186/1476-4598-9-278.

38. Konecny G.E., Glas R., Dering J. et al. Activity of the multikinase inhibitor dasatinib against ovarian cancer cells. Br J Cancer 2009;101(10):1699-708. DOI: 10.1038/sj.bjc.6605381.

39. Ortona E., Pierdominici M., Berstein L. Autoantibodies to estrogen receptors and their involvement in autoimmune diseases and cancer. J Steroid Biochem Mol Biol 2014;144(Pt. B):260-7. DOI: 10.1016/j.jsbmb.2014.07.004.

40. Berstein L.M. Role of endocrinegenotoxic switchings in cancer and other human diseases: basic triad. Adv Exp Med Biol 2008;630:35-51. DOI: $10.1007 / 978-0-387-78818-03$.

41. Berstein L., Tsyrlina E., Poroshina T. et al. Switching (overtargeting) of estrogen effects and its potential role in hormonal carcinogenesis. Neoplasma 2002;49(1):21-5

42. Davies C., Godwin J., Gray R. et al. Relevance of breast cancer hormone receptors and other factors to the efficacy of adjuvant tamoxifen: patient-level metaanalysis of randomised trials. Lancet 2011;378(9793):771-84 DOI: 10.1016/S0140-6736(11)60993-8.

43. Yamamoto-Ibusuki M., Arnedos M., André F. Targeted therapies for ER+/ HER2-metastatic breast cancer. BMC Med 2015;13:137. DOI: 10.1186/s12916-015-0369-5.

44. Safety and efficacy of exemestane plus dasatinib versus placebo for advanced $\mathrm{ER}+$ breast cancer. Clinical Trial. Identifier: NCT00767520. Avaliable at: https://clinicaltrials.gov/ct2/show/ NCT00767520.

45. Randomized phase II trial of letrozole with or without dasatinib as first and second-line treatment for hormone receptor-positive, HER2-negative postmenopausal breast cancer that is unresectable, locally recurrent or metastatic Clinical Trial. Identifier: NCT00696072. Avaliable at: https://clinicaltrials.gov/ct2/ show/results/NCT00696072.

46. Trial of fulvestrant, MK-0646, and dasatinib for metastatic hormone receptor-positive HER2-negative breast cancer. Clinical Trial. Identifier: NCT00903006. Avaliable at: https:// clinicaltrials.gov/ct2/show/results/ NCT00903006.
47. Randomized trial of fulvestrant with or without dasatinib in men and postmenopausal women who have hormone receptor-positive advanced breas cancer previously treated with an aromatase inhibitor. Clinical Trial. Identifier: NCT00754325. Avaliable at: https://clinicaltrials.gov/ct2/show/results/ NCT00754325?term $=$ dasatinib\&cond $=$ br east + cancer $\&$ draw $=2 \&$ rank $=10$.

48. Fulvestrant with or without bortezomib in patients with inoperable locally advanced or metastatic estrogen receptor positive breast cancer. Clinical Trial. Identifier: NCT01142401. Avaliable at: https://clinicaltrials.gov/ct2/show/ NCT01142401.

49. Teng Y.Q., Jin H., Liu Z.Y. et al. The LynSIRT1 signaling pathway is involved in imatinib resistance in chronic myeloid leukaemia. Am J Transl Res 2020;12(6):2711-25.

50. Berstein L.M., Wang J.P., Zheng H. et al. Long-term exposure to tamoxifen induces hypersensitivity to estradiol. Clin Cancer Res 2004;10(4):1530-4. DOI: 10.1158/1078-0432.ccr-0433-03.

51. Berstein L.M., Zheng H., Yue W. et al. New approaches to the understanding of tamoxifen action and resistance. Endocr Relat Cancer 2003;10(2):267-77. DOI: $10.1677 /$ erc. 0.0100267 .

52. Jeng M.H., Yue W., Eischeid A. et al. Role of MAP kinase in the enhanced cell proliferation of long term estrogen deprived human breast cancer cells. Breast Cancer Res Treat 2000;62(3):167-75. DOI: 10.1023/a:1006406030612.

53. Santen R.J., Song R.X., Zhang Z., Kumar R. et al. Long-term estradiol deprivation in breast cancer cells up-regulates growth factor signaling and enhances estrogen sensitivity. Endocr Relat Cancer 2005;12(Suppl 1):S61-73. DOI: $10.1677 /$ erc. 1.01018 .

54. Дронова Т.А., Бабышкина Н.Н., Завьялова М.В. и др. Взаимосвязь компонентов EGFR/PI3K/AKT-сигнального пути с эффективностью терапии тамоксифеном у больных эстрогензависимым раком молочной железы. Успехи молекулярной онкологии 2018;5(3):40-50. [Dronova T.A., Babyshkina N.N., Zavyalova M.V. et al. Relation of EGFR/PI3K/AKT signaling components with tamoxifen efficacy in patients with estrogen-dependent breast cancer. Uspekhi molekulyarnoy onkologii $=$ Advances in Molecular Oncology 2018;5(3):40-50. (in Russ.)]. DOI: 10.17650/2313-805X-2018-5-3-40-50. 55. Dronova T.A., Babyshkina N.N., Zavyalova M.V. et al.Vascular endothelial growth factor receptor 2 (VEGFR2) contributes to tamoxifen resistance in estrogen-positive breast cancer patients. Mol Biol (Mosk) 2021;55(1):118-25. DOI: $10.31857 /$ S0026898421010055. 
56. Красильников М.А., Щербаков А.М. Сигнальные пути, регулируемые эстрогенами, и их роль в опухолевой прогрессии: новые факты и направления поиска. Успехи молекулярной онкологии 2014;1(1):18-26. [Krasil'nikov M.A., Shcherbakov A.M. Estrogen-dependent signaling pathways and their role in the tumor progression: progress and perspectives. Uspekhi molekulyarnoy onkologii $=$ Advances in Molecular Oncology 2014;1(1):18-26. (In Russ.)]. DOI: 10.17650/2313-805X.2014.1.1.18-26.

57. Scherbakov A.M., Sorokin D.V., Tatarskiy V.V. et al. The phenomenon of acquired resistance to metformin in breast cancer cells: The interaction of growth pathways and estrogen receptor signaling. IUBMB Life 2016;68(4): 281-92. DOI: 10.1002/iub.1481.

58. Семина С.Е., Багров Д.В., Красильников М.А. Межклеточные взаимодействия и развитие гормональной резистентности клеток рака молочной железы. Успехи молекулярной онкологии 2015;2(2):50-5. [Semina S.E., Bagrov D.V., Krasil'nikov M.A. Intercellular interactions and progression of hormonal resistance of breast cancer cells. Uspekhi molekulyarnoy onkologii $=$ Advances in Molecular Oncology 2015;2(2):50-5. (In Russ.)]. DOI: 10.17650/2313-805X.2015.2.2.50-55.

59. Сорокин Д.В., Андреева О.Е., Михаевич Е.И. и др. Эффект негативной регуляции эстрогенового сигналинга под действием экзосом: роль в развитии резистентности клеток рака молочной железы. Успехи молекулярной онкологии 2020;7(3):58-62. [Sorokin D.V., Andreeva O.E., Mikhaevich E.I. et al. Effect of the exosome-mediated suppression of the estrogen signaling: the role in the progression of the hormonal resistance of breast cancer cells. Uspekhi molekulyarnoy onkologii $=$ Advances in Molecular Oncology 2020;7(3):58-62. (In Russ.)]. DOI: 10.17650/2313-805X2020-7-3-58-62.

60. Малек А.В., Берштейн Л.М. МикроPHК: половые гормоны, гормональный канцерогенез, гормоночувствительность опухолевой ткани. Успехи молекулярной онкологии 2015;2(1):004-012. [Malek A.V., Bershtein L.M. MicroRNA: sex steroids, hormonal carcinogenesis, hormonal sensitivity of tumor tissue. Uspekhi molekulyarnoy onkologii $=$ Advances in Molecular Oncology 2015;2(1):004012. (In Russ.)]. DOI: 10.17650/2313805X.2015.2.1.004-012.

61. Kalinina T., Kononchuk V., Alekseenok E. et al. Expression of estrogen receptorand progesterone receptor-regulating
microRNAs in breast cancer. Genes

(Basel) 2021;12(4):582.

DOI: $10.3390 /$ genes 12040582 .

62. Sukocheva O.A., Lukina E., Friedemann M. et al. The crucial role of epigenetic regulation in breast cancer anti-estrogen resistance: current findings and future perspectives. Semin Cancer Biol 2020:S1044-579X(20)30263-7. DOI: 10.1016/j.semcancer.2020.12.004.

63. Jeselsohn R., Yelensky R., Buchwalter G. et al. Emergence of constitutively active estrogen receptor- $\alpha$ mutations in pretreated advanced estrogen receptorpositive breast cancer. Clin Cancer Res 2014;20(7):1757-67.

DOI: 10.1158/1078-0432.CCR-13-2332.

64. Hartmaier R.J., Trabucco S.E., Priedigkeit N. et al. Recurrent hyperactive ESR1 fusion proteins in endocrine therapy-resistant breast cancer. Ann Oncol 2018;29(4):872-80. DOI: $10.1093 /$ annonc/mdy025.

65. Gates L.A., Gu G., Chen Y. et al. Proteomic profiling identifies key coactivators utilized by mutant ER $\alpha$ proteins as potential new therapeutic targets. Oncogene 2018;37(33):4581-98. DOI: $10.1038 / \mathrm{s} 41388-018-0284-2$.

66. Chandarlapaty S., Chen D., He W. et al. Prevalence of ESR1 mutations in cell-free DNA and outcomes in metastatic breast cancer: a secondary analysis of the BOLERO-2 clinical. JAMA Oncol 2016;2(10):1310-5. DOI: 10.1001/jamaoncol.2016.1279.

67. Babyshkina N., Vtorushin S., Zavyalova M. et al. The distribution pattern of ER $\alpha$ expression, ESR1 genetic variation and expression of growth factor receptors: association with breast cancer prognosis in Russian patients treated with adjuvant tamoxifen. Clin Exp Med 2017;17(3):383-93. DOI: $10.1007 / \mathrm{s} 10238-016-0428-z$.

68. Babyshkina N., Vtorushin S., Dronova T. et al. Impact of estrogen receptor $\alpha$ on the tamoxifen response and prognosis in luminal-A-like and luminal-B-like breast cancer. Clin Exp Med 2019;19(4):547-56. DOI: 10.1007/s10238-019-00583-6.

69. Backes F.J., Walker C.J., Goodfellow P.J. et al. Estrogen receptor-alpha as a predictive biomarker in endometrioid endometrial cancer. Gynecol Oncol 2016;141(2):312-7. DOI: 10.1016/j.ygyno.2016.03.006.

70. Fiorillo M., Sanchez-Alvarez R., Sotgia F., Lisanti M.P. The ER-alpha mutation Y537S confers Tamoxifen-resistance via enhanced mitochondrial metabolism, glycolysis and Rho-GDI/PTEN signaling: Implicating TIGAR in somatic resistance to endocrine therapy. Aging (Albany NY)
2018;10(12):4000-23.

DOI: 10.18632 /aging. 101690.

71. Jordan V.C. $50^{\text {th }}$ anniversary of the first clinical trial with ICI 46,474 (tamoxifen): then what happened? Endocr Relat Cancer 2021;28(1):R11-30. DOI: 10.1530/ERC-20-0335.

72. Berry N.B., Fan M., Nephew K.P. Estrogen receptor-alpha hinge-region lysines 302 and 303 regulate receptor degradation by the proteasome. Mol Endocrinol 2008;22(7):1535-51. DOI: $10.1210 / \mathrm{me} .2007-0449$.

73. Lee C.I., Goodwin A., Wilcken N. Fulvestrant for hormone-sensitive metastatic breast cancer. Cochrane Database f Syst Rev 2017;1(1):CD011093. DOI: 10.1002/14651858.CD011093. pub2.

74. Khisamov A.A., Manujlova O.O., Byakhov M.Y. Mechanisms of development and the ways to overcome endocrine resistance in breast cancer. Malignant Tumours 2015;4:52-61.

DOI: 10.18027/2224-5057-2015-4-52-61.

75. Jeselsohn R., Bergholz J.S., Pun M. et al. Allele-specific chromatin recruitment and therapeutic vulnerabilities of ESR1 activating mutations. Cancer Cell 2018;33(2):173-86.e5. DOI: 10.1016/j.ccell.2018.01.004.

76. Abderrahman B., Maximov P.Y., Curpan R.F. et al. Pharmacology and molecular mechanisms of clinically relevant estrogen estetrol and estrogen mimic BMI-135 for the treatment of endocrine-resistant breast cancer. Mol Pharmacol 2020;98(4):364-81. DOI: $10.1124 /$ molpharm.120.000054.

77. Abderrahman B., Maximov P.Y., Curpan R.F. et al. Rapid induction of the unfolded protein response and apoptosis by estrogen mimic TTC-352 for the treatment of endocrine-resistant breast cancer. Mol Cancer Ther 2021;20(1):11-25. DOI: 10.1158/1535-7163.MCT-20-0563.

78. Hiscox S., Barrett-Lee P., Borley A.C., Nicholson R.I. Combining Src inhibitors and aromatase inhibitors: a novel strategy for overcoming endocrine resistance and bone loss. Eur J Cancer 2010;46(12):2187-95. DOI: 10.1016/j.ejca.2010.04.012.

79. Larsen S.L., Laenkholm A.V., DuunHenriksen A.K. et al. SRC drives growth of antiestrogen resistant breast cancer cell lines and is a marker for reduced benefit of tamoxifen treatment. PLoS One 2015;10(2): e0118346. DOI: 10.1371/journal.pone.0118346.

80. Zhou J., Xu M., Le K., et al. SRC promotes tamoxifen resistance in breast cancer via up-regulating SIRT1. Onco Targets Ther 2020;13:4635-47. DOI: 10.2147/OTT.S245749. 


\section{Вклад авторов}

В.В. Тихонова: анализ публикаций по теме статьи, написание текста статьи;

Ю.П. Финашутина: анализ и обобщение данных литературы, написание текста статьи;

Л.А. Кесаева: сбор и обработка данных, редактирование статьи.

Authors' contributions

V.V. Tikhonova: reviewed relevant publications, article writing;

Y.P. Finashutina: analysis and generalization of literature data, article writing;

L.A. Kesaeva: obtaining data for analysis, analysis of the obtained data, scientific editing of the article.

ORCID авторов / ORCID of authors

В.В. Тихонова / V.V. Tikhonova: https://orcid.org/0000-0002-8658-2819

Ю.П. Финашутина / Y.P. Finashutina: https://orcid.org/0000-0002-6154-535X

Л.А. Кесаева / L.A. Kesaeva: https://orcid.org/0000-0001-8277-8649

Конфликт интересов. Авторы заявляют об отсутствии конфликта интересов.

Conflict of interest. The authors declare no conflict of interest.

Финансирование. Работа выполнена без спонсорской поддержки.

Financing. The work was performed without external funding. 